OPEN ACCESS

Edited by:

Juan A. Tovar,

University Hospital La Paz, Spain

Reviewed by:

Daniele Alberti,

University of Brescia, Italy

Luca Pio,

Hôpital Robert Debré, France

Francisco Hernández Oliveros, University Hospital La Paz, Spain

*Correspondence:

Jung-Man Namgoong namgoong2940@gmail.com

Specialty section:

This article was submitted to

Pediatric Surgery,

a section of the journal

Frontiers in Pediatrics

Received: 30 November 2020

Accepted: 08 February 2021

Published: 26 February 2021

Citation:

Cho YJ, Namgoong J-M, Kwon HH, Kwon YJ, Kim DY and Kim SC (2021) The Advantages of Indocyanine Green

Fluorescence Imaging in Detecting and Treating Pediatric Hepatoblastoma: A Preliminary Experience. Front. Pediatr. 9:635394. doi: 10.3389/fped.2021.635394

\section{The Advantages of Indocyanine Green Fluorescence Imaging in Detecting and Treating Pediatric Hepatoblastoma: A Preliminary Experience}

\author{
Yu Jeong Cho, Jung-Man Namgoong*, Hyun Hee Kwon, Yong Jae Kwon, Dae Yeon Kim \\ and Seong Chul Kim
}

Department of Pediatric Surgery, Asan Medical Center Children's Hospital, University of Ulsan College of Medicine, Seoul, South Korea

Background: Currently, indocyanine green (ICG) fluorescence imaging enables radical surgical resection in hepatoblastoma (HB) and has beneficial uses; however, its usage in pediatric patients is still limited.

Methods: From 2015 to 2019, 17 hepatoblastoma patients underwent 22 fluorescence-guided surgery using ICG. ICG $(0.3 \mathrm{mg} / \mathrm{kg})$ was intravenously injected 24-48 h before the operation. With ICG/NIR camera, intraoperative identification of biological structures and demarcation of mass were conducted.

Results: ICG fluorescence-guided surgery was performed for hepatoblastoma in 22 cases: 16, 1, and 2 cases underwent anatomic resection, partial hepatectomy, and liver transplantation, respectively. Six patients accompanied lung metastasis at the time of surgery, and two patients underwent lung surgery using ICG. The median interval from ICG injection to surgery was 38.3 h (range, 20.5-50.3 h). The median tumor size was $36.5 \mathrm{~mm}$ (range, 2-132 $\mathrm{mm}$ ). According to the pathologic finding, the median safety margin was secured for $6 \mathrm{~mm}$ (range, $0-11 \mathrm{~mm}$ ) and there was no residual finding at the liver at the follow-up computed tomography (CT).

Conclusions: ICG fluorescence imaging in children with HB was feasible and safe for tumor demarcation and enhancing the accuracy of radical tumor resection.

Keywords: indocyanine green, hepatoblastoma, fluorescence, pediatrics, $\mathrm{R} 0$ resection

\section{INTRODUCTION}

Chemotherapy has been used effectively to treat hepatoblastoma (HB), but complete liver resection is the gold standard treatment for this cancer. Recently, imaging modalities have improved; however, the resection range and intraoperative diagnosis of small tumors remain challenging.

Ishizawa et al. first introduced the indocyanine green (ICG) fluorescence technique in 2009 to enhance the accuracy of the liver resection procedure during hepatocellular carcinoma (HCC) surgeries (1). Protein-bound ICG emits light in the excitation spectrum at $750-810 \mathrm{~nm}$, which can be visualized under near-infrared (NIR) illumination (2). ICG is extracted from the blood by 
normal hepatocytes and excreted into the bile. HCC cells do not excrete ICG; it is retained in HCC cells and can be detected using a camera up to several days (3). ICG imaging technique enabled highly sensitive identification of HCCs by visualizing the disordered biliary excretion of ICG.

ICG fluorescence imaging to detect HCC depended on the hepatic clearance of this compound. The pathophysiological mechanisms underlying ICG emission are not fully understood but may be associated with hepatocyte-to-bile duct secretion. It is well-established that hepatocytes take up ICG selectively taken via two membrane transport systems: OATP1B3 (transporter belonging to the family of OATP or organic anion transporters) and NTCP (Na+/taurocholate co-transporting polypeptide) (4). It was reported previously that well-differentiated HCC lesions exhibit fluorescence, whereas the tissues of poorly differentiated HCCs and colorectal tumor metastases cannot be visualized with this fluorescent marker (1). There is no study on the mechanism of action of ICG in HB; however, we can assume that HB, which is pathologically similar to HCC, can be visualized based on the disordered biliary excretion of ICG $(5,6)$.

We hypothesized that this imaging method could help treat $\mathrm{HB}$ as in HCC. Yamada et al. and Yamamichi et al. applied surgical navigation using ICG fluorescence imaging to detect HB lesions and demonstrated its usefulness in the complete resection of $\mathrm{HB}(7,8)$. Other authors have reported similar results. In this single-center case series study, we evaluated the usefulness of ICG in treating pediatric HB cases, taking into account the postoperative outcomes.

\section{MATERIALS AND METHODS}

We retrospectively reviewed all children who underwent $\mathrm{HB}$ surgical resection assisted by ICG fluorescence imaging between January 2015 and October 2019 at Asan Medical Center, Seoul, Korea. As this is an exploratory study, statistical power was not estimated. We collected data from the medical records including patient demographics, HB characteristics such as the tumor's size and depth from the liver surface measured by preoperative contrast-enhanced computed tomography (CT), the interval time between ICG injection and surgery, type of liver resection, pattern of immunofluorescence (diffuse or uneven) pathological findings, and follow-up.

The primary endpoint was ICG imaging's feasibility in exactly demarcating $\mathrm{HB}$. The secondary endpoints were disease-free survival and HB recurrence at the follow-up period. ICG was intravenously injected before surgery in each patient $(0.3 \mathrm{mg} / \mathrm{kg}$ of body weight). The interval between the ICG injection and surgery was 1 or 2 days, which was set to decrease false-positive results based on our experience and other previous studies (2, 811). A $10 \mathrm{~mm}$ endoscopic NIR camera system (D-Light P, Karl Storz SE \& Co. KG, Tuttlingen, Germany) was used for the intraoperative ICG fluorescence imaging. It activates molecules with emitted light at $835 \mathrm{~nm}$ wavelength and filters out light with a wavelength (12). In this device, the camera unit was directly handled, and intraoperative fluorescence images were observed on a monitor. Therefore, ICG-stained HB cells could be detected, being distinguishable from normal hepatocytes. Before tumor resection, the lesion area was identified by the ICG/NIR camera at $10-20 \mathrm{~cm}$ from the site of suspicion to demarcate the resection range. This enables us to visualize the ICG fluorescence image as it appears in the macroscopic view. The monitoring mode could be switched instantly between ICF fluorescence and normal imaging by turning on/off the ICG/NIR with one button. After resection, the fluorescence presence was evaluated again using the ICG/NIR camera in both the specimen and the resected area in real-time. Additional resection was performed if there was no remaining fluorescence in the resected area.

All the procedures described in this study were conducted following the standards of the Ethics Committee of Asan Medical Center Children's Hospital, Ulsan University (IRB No. 2019-0441).

\section{RESULTS}

In the time span of the study, 17 pediatric $\mathrm{HB}$ patients were subjected to ICG fluorescence imaging in 22 separate surgeries at our hospital. Imaging was conducted based on the patient's condition, metastatic lung tumor, liver transplantation, and anatomical resection requirements. The procedures were performed by pediatric surgeons as follows: 17 liver resections for 15 patients, 2 liver transplants (Table 1), and 3 other surgeries for lung metastases $(n=2)$ and lymph-node metastasis above the diaphragm $(n=1)$ which was done with liver resection or liver transplantation (Table 2).

None of these patients had an allergic or adverse reaction to ICG. The median age and weight of the patients at the time of their surgery were 18 months (range, $4-140$ months) and $9.9 \mathrm{~kg}$ $(6.2-33.9 \mathrm{~kg})$, respectively. The median interval time between the ICG injection and surgery was $38.3 \mathrm{~h}$ (range, 20.5-50.3 h). The median size of the tumor was $36.5 \mathrm{~mm}$ (2-132 mm, except in liver transplantation cases). There were no $\mathrm{HB}$ lesions at a depth of more than $10 \mathrm{~mm}$ from the liver/lung surface, except in one case with segment II (S2) daughter nodules (Pt. No. 10) (defined as small nodular lesions around the main tumor) (13). Liver tumors at a depth of $<10 \mathrm{~mm}$ in the liver/lung surface were clearly visible under the ICG/NIR camera. The patients were all pathologically identified as hepatoblastoma, and their subtype were as follows; epithelial and mesenchymal 9, fetal 7, fetal, and embryonal 1.

In this study, 2 cases (Pt. Nos. 2 and 10) required daughter nodule resection during the main $\mathrm{HB}$ resection. In two patients, four nodules were removed with a median size of $10 \mathrm{~mm}$ on the CT image (range, $5-15 \mathrm{~mm}$ ). Of note, one of these nodules was not detected during the preoperative examinations but revealed by the ICG/NIR camera (Figure 1), pathologically diagnosed as $\mathrm{HB}$. The remaining 3 nodules had positive CT and fluorescence imaging findings but pathologically, were not $\mathrm{HB}$.

In this series, two patients (Pt. Nos. 7 and 10) underwent a two-stage hepatectomy due to insufficient future liver remnant volume. In the second-stage resection in Pt. 10, S2 daughter nodules, confirmed by CT, were $15 \mathrm{~mm}$ from the liver surface and were not detected by the ICG/NIR camera; therefore, localization was conducted using intraoperative ultrasonography. 
TABLE 1 | Clinical, pathological, surgical data of 17 children who underwent to ICG guided liver resection/transplantation for HB.

\begin{tabular}{|c|c|c|c|c|c|c|c|c|c|c|c|c|c|c|}
\hline $\begin{array}{l}\text { Pt } \\
\text { no. }\end{array}$ & $\begin{array}{c}\text { Age } \\
\text { (month/sex) }\end{array}$ & $\begin{array}{l}\text { BWT at } \\
\text { surgery }\end{array}$ & PRETEXT & $\begin{array}{l}\text { Tumor } \\
\text { diameter } \\
\text { (cm) }\end{array}$ & $\begin{array}{l}\text { The } \\
\text { number of } \\
\text { tumors } \\
\text { (CT) }\end{array}$ & Metastasis & Invasion & $\begin{array}{c}\text { AFP (ng/dL) } \\
\text { at surgery }\end{array}$ & $\begin{array}{l}\text { Interval time } \\
\text { of ICG } \\
\text { injection/surge } \\
\text { (h) }\end{array}$ & $\begin{array}{l}\text { ICG } \\
\text { Pattern } \\
\text { ery }\end{array}$ & Pathology/Necrosis(\%) & Procedure & $\begin{array}{l}\text { Safety } \\
\text { margin } \\
(\mathrm{cm})\end{array}$ & $\begin{array}{c}\text { Disease- } \\
\text { free } \\
\text { survival } \\
\text { (months) }\end{array}$ \\
\hline 1 & $4 / M$ & 6.2 & III & 2.4 & 1 & & & 88 & 26.3 & diffuse & Fetal $/<5$ & RAS & 0 & 43 \\
\hline 2 & $19 / M$ & 10.5 & IV & $4.7, \mathrm{DN}^{\star} 3$ & 4 & Lung & $\begin{array}{l}\text { Diaphragm, Rt. } \\
\text { adrenal gland }\end{array}$ & 5,830 & 22.7 & uneven & $\begin{array}{c}\text { Epithelial and } \\
\text { mesenchymal/95 }\end{array}$ & $\begin{array}{l}\mathrm{PH}(\mathrm{S} 6-8, \\
\mathrm{S} 2 / \mathrm{pS} 3)\end{array}$ & 2 & 41 \\
\hline 3 & $18 / F$ & 9.8 & $|/| I \mid$ & 6.3 & 1 & & & 14,800 & 26.3 & diffuse & Fetal/0 & $\begin{array}{l}\text { Laparoscopic } \\
\quad \text { LLS }\end{array}$ & 4 & 38 \\
\hline 4 & $13 / F$ & 10 & $\|$ & 2.5 & 1 & & & 30 & 20.5 & diffuse & $\begin{array}{c}\text { Epithelial and } \\
\text { mesenchymal/ }<5\end{array}$ & LLS & 5 & 35 \\
\hline 5 & $10 / M$ & 9.4 & III & 3.9 & 1 & & MHV & 464 & 27.9 & uneven & $\begin{array}{c}\text { Epithelial and } \\
\text { mesenchymal/99 }\end{array}$ & CBS & 0 & 17 \\
\hline 6 & $140 / F$ & 33.9 & 1 & 13.2 & 1 & & & 19,199 & 27.0 & uneven & Fetal and embryonal/10 & LLS & 11 & 12 \\
\hline \multirow[t]{2}{*}{7} & $43 / F$ & 9.4 & IV & $3.4, \mathrm{DN}^{*} 6$ & 7 & Lung & & 791 & 23.2 & diffuse & Fetal/80 & $\mathrm{RH}$ & 3 & 8 \\
\hline & $46 / F$ & 10.2 & & 4 & 1 & & & 55.2 & 39.3 & uneven & $\begin{array}{c}\text { Fetal and Chemotherapy- } \\
\text { associated } \\
\text { vasculopathy/unknown }\end{array}$ & LLS & 0 & \\
\hline 8 & $6 / M$ & 7.1 & III & 5.5 & 1 & & IVC, PV & 508 & 45.7 & undetected & Fetal/80 & RTS, $\mathrm{PH}(\mathrm{S} 1)$ & 1 & 7 \\
\hline 9 & $16 / M$ & 9 & III & $5.7, \mathrm{DN}^{*} 4$ & 5 & Lung & Diaphragm & 471 & 37.3 & uneven & $\begin{array}{c}\text { Epithelial and } \\
\text { mesenchymal/90 }\end{array}$ & $\mathrm{ERH}$ & 0.2 & 7 \\
\hline \multirow[t]{2}{*}{10} & 70/F & 14.6 & III & $7, \mathrm{DN}^{\star 2}$ & 3 & Lung & Rt. adrenal gland & 2,710 & 41.2 & diffuse & Fetal/40 & ERH, PH(S2) & & 4 \\
\hline & $72 / F$ & 15.1 & & $0.5,1.4$ & 3 & & & 16 & 40.3 & diffuse & Fetal/unknown & $\begin{array}{l}\text { Segmentectomy } \\
\quad(\mathrm{S} 2, \mathrm{~S} 4)\end{array}$ & 0.3 & \\
\hline 11 & $5 / M$ & 6.9 & III & 4.8 & 1 & & & 207 & 40.0 & uneven & $\begin{array}{c}\text { Epithelial and } \\
\text { mesenchymal/ }<5\end{array}$ & CBS & 0 & 5 \\
\hline 12 & $15 / M$ & 9.3 & $\|$ & $4.6,4.8$ & 2 & & & 3,060 & 41.2 & undetected & $\begin{array}{c}\text { Epithelial and } \\
\text { mesenchymal/unknown }\end{array}$ & CBS & 0.9 & 6 \\
\hline 13 & $9 / F$ & 8 & III & 6.1 & 1 & & IVC & 70 & 39.9 & diffuse & $\begin{array}{l}\text { Epithelial and } \\
\text { mesenchymal/0 }\end{array}$ & $\mathrm{RH}, \mathrm{S} 1$ & 0 & 5 \\
\hline 14 & $12 / M$ & 9.6 & III & 4.9 & 1 & & & 769 & 41.5 & diffuse & $\begin{array}{c}\text { Epithelial and } \\
\text { mesenchymal/30 }\end{array}$ & RTS & 0.2 & 2 \\
\hline 15 & $71 / F$ & 20.5 & III & 6.2 & 1 & Lung & & 13,000 & 42.3 & uneven & Fetal/15 & $\mathrm{LH}$ & 2.5 & 2 \\
\hline 16 & $96 / M$ & 28 & IV & 13.2 & Multi & & $\begin{array}{l}\text { Diaphragm, } \\
\text { RHV/MHV } \\
\text { RHV/MHV }\end{array}$ & 30,500 & 36.7 & uneven & Fetal/7 & LT & none & 10 \\
\hline 17 & $18 / F$ & 10.1 & IV & 10.5 & Multi & Lung & & 237 & 50.3 & uneven & $\begin{array}{c}\text { Epithelial and } \\
\text { mesenchymal/30 }\end{array}$ & LT & none & 2 \\
\hline
\end{tabular}

$E R H$, extended right hepatectomy; $R(L) H$, right(left) hepatectomy; $P H$, partial hepatectomy; CBS, central bisegmentectomy; $R(L) T S$, right(left) trisegmentectomy; LTx, liver transplantation; LLS, left lateral segmentectomy; RAS, right anterior segmentectomy: DN, daughter nodule; MHV, middle hepatic vein; IVC, inferior vena cava; PV, portal vein; RHV, right hepatic vein; MHV, middle hepatic vein. 
TABLE 2 | ICG fluorescence imaging of three surgeries for metastases.

\begin{tabular}{|c|c|c|c|c|c|c|c|c|c|c|c|}
\hline $\begin{array}{l}\text { Patient } \\
\text { no. }\end{array}$ & $\begin{array}{l}\text { t Age } \\
\text { (months)/sex }\end{array}$ & $\begin{array}{l}\text { BWT at } \\
\text { surgery }\end{array}$ & Metastasis & Pathology & $\begin{array}{l}\text { Tumor } \\
\text { diameter } \\
\text { (cm) }\end{array}$ & $\begin{array}{l}\text { The number } \\
\text { of tumors } \\
\text { (CT) }\end{array}$ & $\begin{array}{l}\text { AFP (ng/dL) } \\
\text { at surgery }\end{array}$ & $\begin{array}{l}\text { Interval time } \\
\text { of ICG } \\
\text { injection/surg } \\
\text { (h) }\end{array}$ & $\begin{array}{l}\text { ICG pattern } \\
\text { gery }\end{array}$ & Procedure & $\begin{array}{c}\text { Disease- } \\
\text { free } \\
\text { survival } \\
\text { (months) }\end{array}$ \\
\hline 2 & $19 / \mathrm{M}$ & 10.5 & Lung, Rt & Non-malignant & 1.5 & 1 & 5,830 & 22.7 & diffuse & $\begin{array}{l}\text { Right wedge } \\
\text { resection }\end{array}$ & 41 \\
\hline 10 & $76 / \mathrm{M}$ & 15.5 & $\begin{array}{c}\text { LN above } \\
\text { diaphragm, Rt }\end{array}$ & Fetal & 2.5 & 1 & 2,520 & 31 & diffuse & Excision & 4 \\
\hline 17 & $18 / F$ & 10.1 & Lung, Rt & $\begin{array}{l}\text { Epithelial and } \\
\text { mesenchymal }\end{array}$ & $0.8,0.9,1$ & 3 & 237 & 42.3 & diffuse & $\begin{array}{l}\text { Right wedge } \\
\text { resection }\end{array}$ & 2 \\
\hline
\end{tabular}
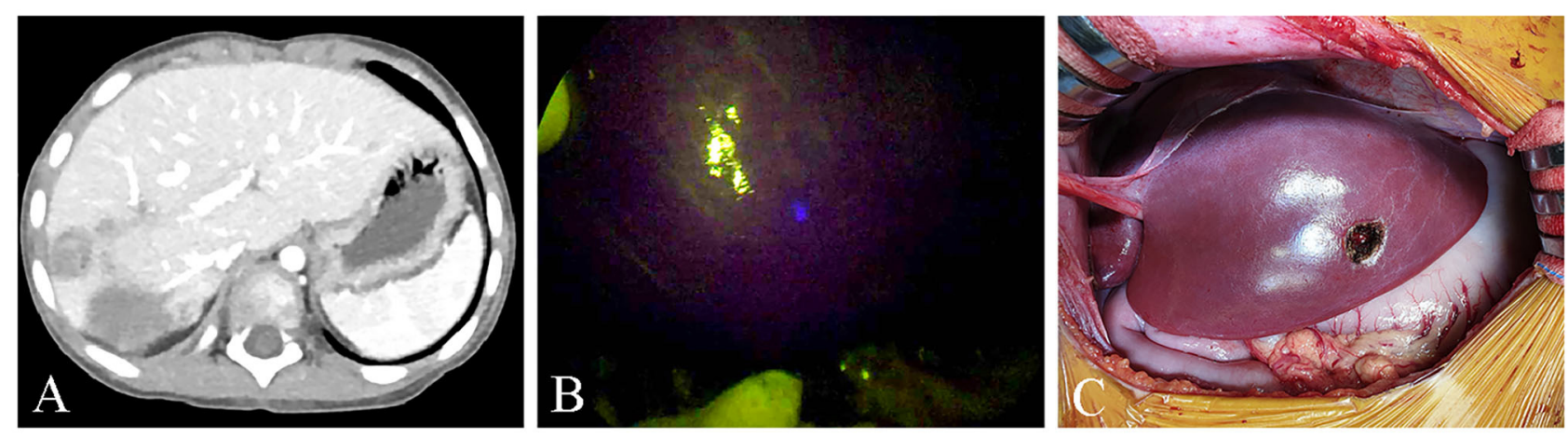

FIGURE 1 | (A,B) One nodule was not seen on the pre-operative computed tomography (CT) but was seen on ICG/NIR camera. (C) Gross morphology.

In two children with $\mathrm{HB}$ who underwent liver transplantation (Table 1), a successful inferior vena cava (IVC) demarcation was performed using ICG fluorescence imaging for safe vascular reconstruction. None of the patients who underwent primary HB resection had recurrence until now.

\section{DISCUSSION}

Up to now $<50$ children underwent to surgery for liver or metastatic HB with the aid of ICG fluorescence $(7,8,10,11$, 14-17). We evaluated the potential role of intraoperative ICG fluorescence imaging in improving the radical resection of $\mathrm{HB}$ in a series of 17 consecutive children. ICG is a safe agent widely used to estimate liver function and assist in hepatectomy strategies for HCC and colorectal carcinoma metastases $(1,18)$. Our findings suggest that ICG fluorescence imaging can enable the delineation of liver segments or subsegments containing $\mathrm{HB}$ by visualizing the ICG retained in these lesions (Figure 2).

The major advantages of fluorescence imaging include feasibility and safety. In this case series, fluorescent images of the liver regions were obtained in real-time during the operation by placing the camera on the liver surface before resection and the raw surface during the transaction. Furthermore, only a low incidence of adverse reactions has been reported after intravenous ICG injection (19).
In this cohort, the intraoperative fluorescent finding was undetectable in Pt. Nos. 8 and 12, both with a high necrosis rate after chemotherapy (No. 8 , necrosis $80 \%$; No. 12 , osseous bone differentiation/calcification). Except for these two cases, the remaining cases successfully achieved the visualization of primary HB lesions, whether in an uneven or diffuse pattern. All patients with $\mathrm{HB}$ underwent chemotherapy sessions before resection; therefore, a percentage of necrotic and fibrotic areas were observed macroscopically. These areas were usually nonfluorescent and had an uneven pattern (Figure 2B). Moreover, $\mathrm{HB}$ with teratoid features might demonstrate non-fluorescence by the same mechanism as a necrotic lesion post-chemotherapy. Ishizawa et al. demonstrated that the fluorescent patterns are closely associated with liver cancer characteristics (20). The number of subjects was small in this study; thus, there was no association between the fluorescence pattern and pathology.

Although pathophysiologic characteristics affect fluorescent signals, the liver tumor detection using the ICG technique mainly depends on the depth from the liver surface because the nearinfrared light penetration depth of human tissue is limited to $5-10 \mathrm{~mm}(1,21,22)$. Kudo et al. reported that tumors located $8 \mathrm{~mm}$ or more from the liver surface were not identified in a series of 16 HCCs and 16 liver metastases resected from 17 patients (21). Similarly, in Pt. No. 10b, in this series, the S2 daughter nodules, evident on contrast-enhanced CT and 

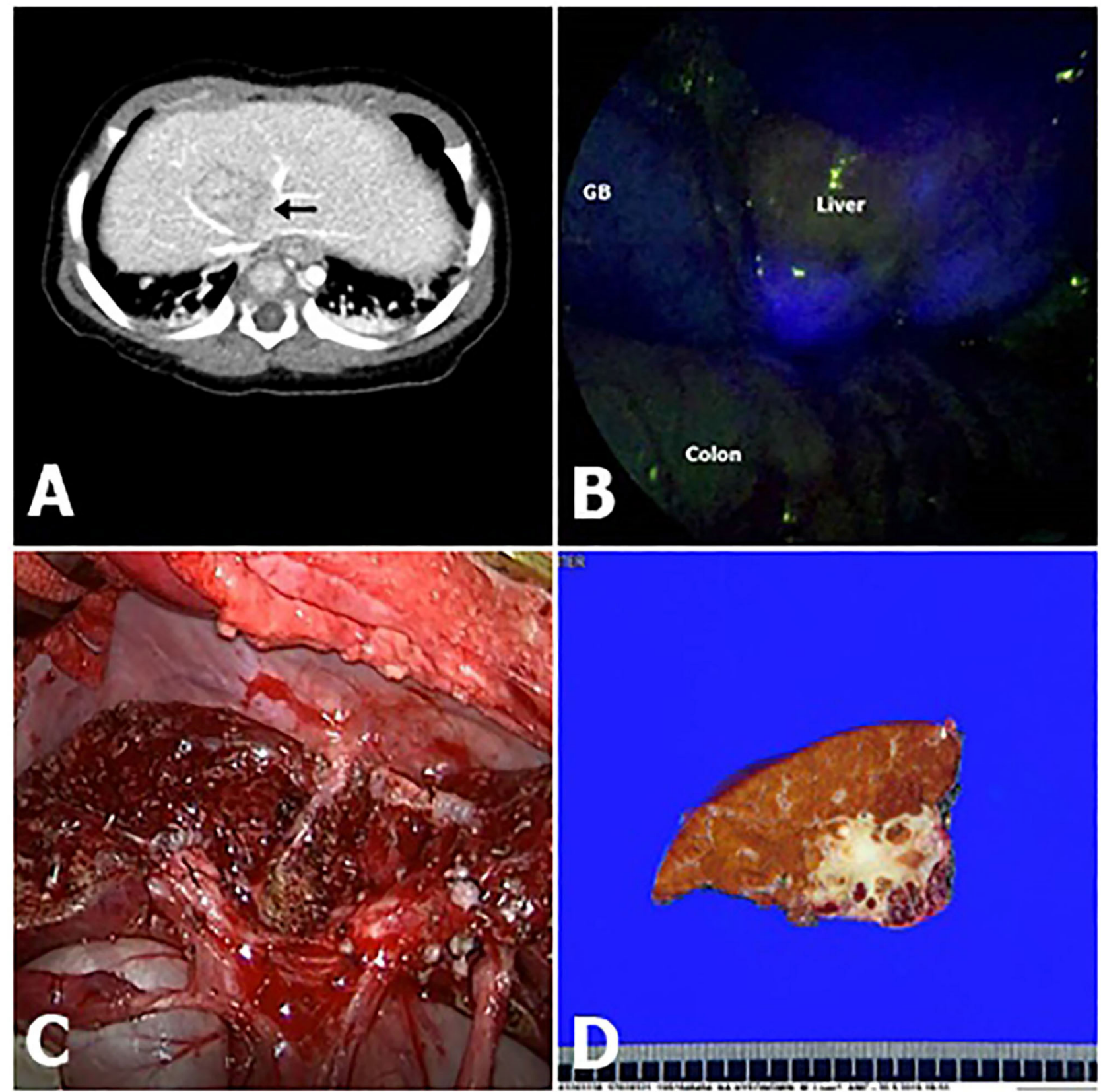

FIGURE 2 | Fluorescence imaging following intravenous ICG (indocyanine green) demonstrated clear delineation (Pt. No. 11 in Table 1). (A) Computed tomography (CT) shows that hepatoblastoma (HB) was attached to major vessels. (B) Intraoperative ICG fluorescence imaging technique showed bright signals at the HB lesion with an uneven pattern. (C) Gross morphology. (D) A photograph of the liver slide of HB, showing that the resection margin is very delicate.

ultrasonography, were at a $15 \mathrm{~mm}$ depth from the liver surface and were undetectable by ICG/NIR camera. In this case, we used intraoperative ultrasonography to localize these lesions. In patients other than Pt. No. 10b, none of the tumors were located at a depth of more than $5 \mathrm{~mm}$ from the liver surface which were identified using the ICG method.

Despite the limitation in detecting deeply located cancers, intraoperative ICG fluorescent imaging is versatile as it is useful not only in visual inspections and palpation but also for detecting small lesions located just beneath the liver surface, compensating the drawbacks of intraoperative ultrasonography and those of laparoscopic and thoracoscopic surgery. Furthermore, this technique can detect residual cancerous tissues on the raw surface of the remnant liver after resection, which is proven to be very useful in a two-stage hepatectomy. Pt. Nos. 7 and 10 underwent a two-stage hepatectomy with prior planning for 

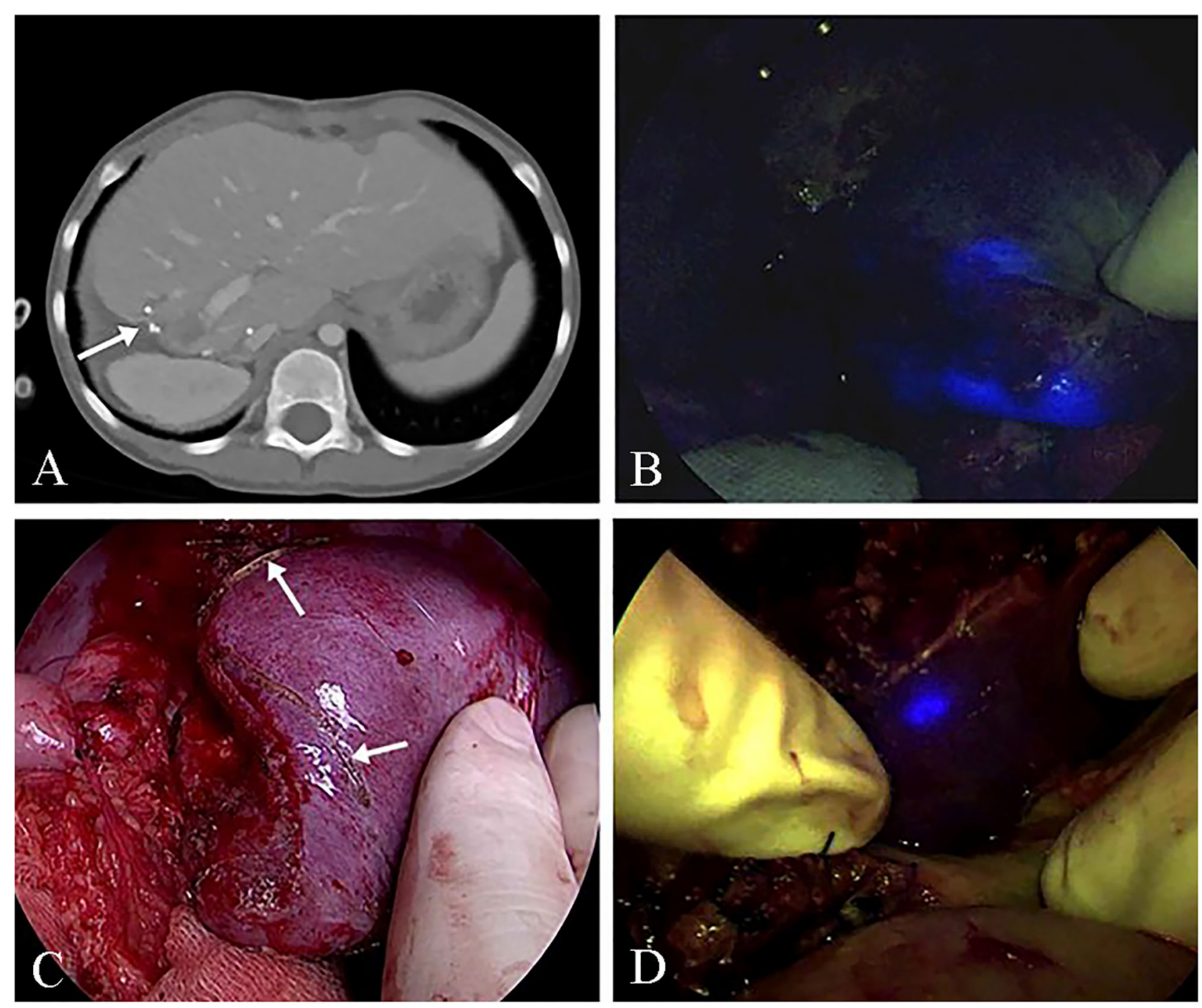

FIGURE 3 | ICG (indocyanine green) fluorescence imaging of the remnant lesion at the two-stage hepatectomy (Pt. No. 10b in Table 1). (A) Computed tomography (CT) shows remnant HB lesions before the second-stage operation. (B) The intraoperative ICG fluorescence imaging technique showed the remnant HB lesions. (C) The delineation of the remnant HB lesion S4. (D) An additional resection for the fluorescence remaining in the resected area.

a $25-30 \%$ future liver remnant, considering the postoperative morbidity and mortality $(4,23)$. The lesions were checked using contrast-enhanced CT before the second surgery; however, identifying the remnant lesions boundaries on the raw surface of the remnant liver with visual or intraoperative ultrasonography during the operation is challenging. In this study, we could secure the resection margin of the lesion after the second operation (Figure 3). Regarding the oncologic aspects, this technique could achieve a more effective $\mathrm{HB}$ radical resection, thereby improving the outcomes (23). Besides, postoperative morbidity and mortality could be reduced by guaranteeing future liver remnant.

Another advantage of the ICG technique is its ability to detect small pulmonary metastatic lesions and invade major vessels and the diaphragm adjacent to the HB (Figure 4). In this study, the pulmonary lesions were easily differentiated from the normal lung tissues (Pt. No. 2). There are several reasons why pulmonary lesions were easily detected using ICG fluorescence as follows: clear contrast created due to lack of ICG accumulation in normal lung tissue, typical metastatic lesion location in peripheral areas, and one-lung ventilation (11). The tumor cells of large $\mathrm{HB}$ lesions in the liver sometimes invade the IVC, major vessels, and the diaphragm. Three patients showed fluorescent signals close to the diaphragm, which, in one case (Pt. No. 16), a positive finding was confirmed requiring that part of the diaphragm to be resected en bloc with the liver. Furthermore, when a living donor liver transplantation was performed in this same patient, the ICG technology facilitated the complete resection of the HB lesion surrounding the IVC. As this method was useful in detecting any residual tumor at the 


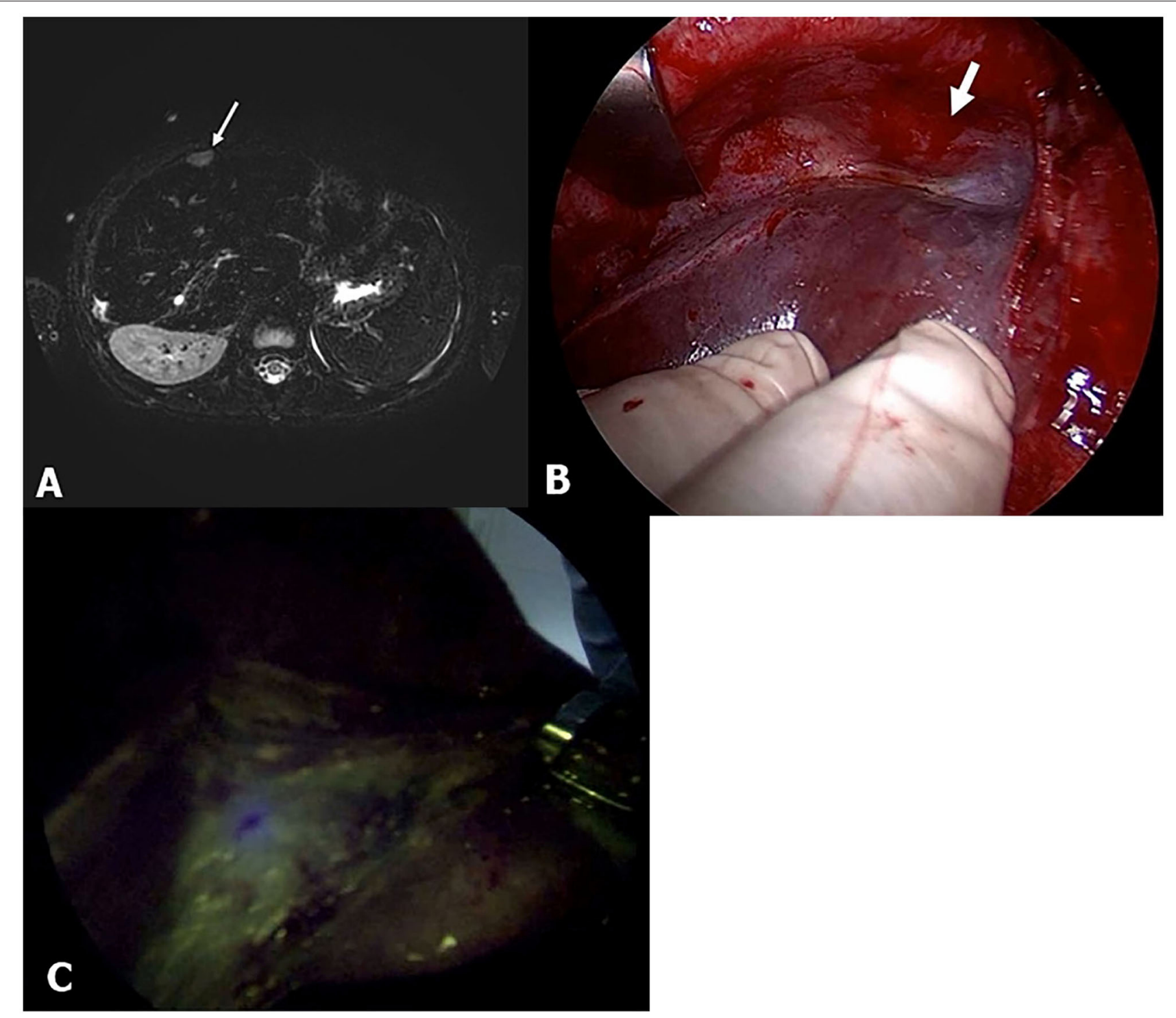

FIGURE 4 | Pt. No. 10 in Table 2: (A) T2-weighted magnetic resonance (MR) showed the supradiaphragm metastatic lesion (white bold arrow). (B) Without fluorescent imaging. (C) Fluorescent imaging enabled visualization of the metastasis of HB that was palpable but clearly unidentified in gross.

resection stump of the IVC, we could determine the stump level that was safe to reconstruct anastomosis with the hepatic vein of the donor liver. Through the ICG fluorescence imaging, we could expect good liver transplantation results by securing safe vascular reconstruction.

The ICG fluorescent imaging technique has several limitations. First, the false-positive rate during surgery is reported to be $10-20 \%$ (11). In this study, eight lesions were identified on contrast-enhanced CT, ultrasonography, and fluorescent imaging. Still, they were not microscopically proved, including six daughter nodules, one metastatic lung tumor, and one invasion of the diaphragm, all $<10 \mathrm{~mm}$. It has been suggested that ICG is sensitive enough to detect lesions as small as $0.062 \mathrm{~mm}$ in diameter (11), so the resected lesions in our study were too small for pathological detection. Paraffin-embedded specimens were sectioned in $\mu \mathrm{m}$. If the lesion is smaller than this, the pathologist could not detect it. Other possibilities of false-positive nodule might be non-specific labeling due to the poor function of non-cancerous tissue such as cirrhosis, bile duct proliferation, expanding cysts, or regenerating nodules (24). The characteristic of false-positive lesions should be clarified in further study populations in pediatrics. Second, ICG fluorescence imaging can be utilized only if the superficial lesion is $<10 \mathrm{~mm}$ deep as the ICG signal cannot penetrate the tissues at a greater depth. It should be taken into account also that our investigation was a single-center study with small sample size, a short follow-up for the majority of our patients, and our results need to be confirmed in a larger series. Given these limitations, this technique can be used as a supplemental modality to existing imaging tests, inspections, and palpation. 


\section{CONCLUSION}

ICG fluorescence imaging is a promising technique that may support $\mathrm{HB}$ surgery as it provides additional information regarding these tumors localization and delineate the boundaries of these lesions. It might help highly sensitive identification of remnant lesions and small and grossly unidentifiable tumors in real-time. Thus, this modality can enhance the accuracy of resections and improve the oncologic results by enabling surgeons to perform R0 resection. Larger multicenter studies with long-term follow-up are warranted to confirm these findings.

\section{DATA AVAILABILITY STATEMENT}

The original contributions presented in the study are included in the article/supplementary material, further inquiries can be directed to the corresponding author.

\section{ETHICS STATEMENT}

The studies involving human participants were reviewed and approved by the Ethics Committee of Asan Medical Center

\section{REFERENCES}

1. Ishizawa T, Fukushima N, Shibahara J, Masuda K, Tamura S, Aoki $\mathrm{T}$, et al. Real-time identification of liver cancers by using indocyanine green fluorescent imaging. Cancer. (2009) 115:2491-504. doi: 10.1002/cncr. 24291

2. Miyata A, Ishizawa T, Tani K, Shimizu A, Kaneko J, Aoki T, et al. Reappraisal of a dye-staining technique for anatomic hepatectomy by the concomitant use of indocyanine green fluorescence imaging. J Am Coll Surg. (2015) 221:e27-36. doi: 10.1016/j.jamcollsurg.2015.05.005

3. Steenks M, Peters J, Rademacher W, Nieuwenhuijs VB, Padbury RT, Barritt GJ. Intermittent ischemia enhances the uptake of indocyanine green to livers subject to ischemia and reperfusion. J Gastroenterol Hepatol. (2017) 32:7017. doi: 10.1111/j.1440-1746.2012.07169.x

4. Romesser PB, Romanyshyn JC, Schupak KD, Setton J, Riaz N, Wolden SL, et al. Percutaneous endoscopic gastrostomy in oropharyngeal cancer patients treated with intensity-modulated radiotherapy with concurrent chemotherapy. Cancer. (2012) 118:6072-8. doi: 10.1002/cncr.27633

5. Zimmermann A. The emerging family of hepatoblastoma tumours: from ontogenesis to oncogenesis. Eur J Cancer. (2005) 41:1503-14. doi: 10.1016/j.ejca.2005.02.035

6. Eichenmuller M, Trippel F, Kreuder M, Beck A, Schwarzmayr $\mathrm{T}$, Haberle $\mathrm{B}$, et al. The genomic landscape of hepatoblastoma and their progenies with HCC-like features. J Hepatol. (2014) 61:1312-20. doi: 10.1016/j.jhep.2014.08.009

7. Yamada Y, Ohno M, Fujino A, Kanamori Y, Irie R, Yoshioka T, et al. Fluorescence-guided surgery for hepatoblastoma with indocyanine green. Cancers (Basel). (2019) 11:1215. doi: 10.3390/cancers11081215

8. Yamamichi $\mathrm{T}$, Oue $\mathrm{T}$, Yonekura $\mathrm{T}$, Owari $\mathrm{M}$, Nakahata $\mathrm{K}$, Umeda S, et al. Clinical application of indocyanine green (ICG) fluorescent imaging of hepatoblastoma. J Pediatr Surg. (2015) 50:833-6. doi: 10.1016/j.jpedsurg.2015.01.014

9. Lim C, Vibert E, Azoulay D, Salloum C, Ishizawa T, Yoshioka R, et al. Indocyanine green fluorescence imaging in the surgical management of liver cancers: current facts and future implications. J Visc Surg. (2014) 151:11724. doi: 10.1016/j.jviscsurg.2013.11.003
Children's Hospital, Ulsan University. Written informed consent to participate in this study was provided by the participants' legal guardian/next of kin. Written informed consent was obtained from the minor(s)' legal guardian/next of kin for the publication of any potentially identifiable images or data included in this article.

\section{AUTHOR CONTRIBUTIONS}

All the authors have contributed to reviewing the literature and provided a succinct account of the surgical treatment of hepatoblastoma in pediatrics.

\section{FUNDING}

This work was supported by the National Research Foundation of Korea (NRF) grant funded by the Korea government (MEST) (2020R1A2C2102137).

\section{ACKNOWLEDGMENTS}

We would like to thank Enago (www.enago.co.kr) for the English language review.

10. Chen-Yoshikawa TF, Hatano E, Yoshizawa A, Date H. Clinical application of projection mapping technology for surgical resection of lung metastasis. Interact Cardiovasc Thorac Surg. (2017) 25:1010-1. doi: 10.1093/icvts/ivx247

11. Kitagawa N, Shinkai M, Mochizuki K, Usui H, Miyagi H, Nakamura $\mathrm{K}$, et al. Navigation using indocyanine green fluorescence imaging for hepatoblastoma pulmonary metastases surgery. Pediatr Surg Int. (2015) 31:407-11. doi: 10.1007/s00383-015-3679-y

12. Quintero J, Miserachs M, Ortega J, Bueno J, Dopazo C, Bilbao I, et al. Indocyanine green plasma disappearance rate: a new tool for the classification of paediatric patients with acute liver failure. Liver Int. (2014) 34:68994. doi: 10.1111/liv.12298

13. Sakuri M, Okamura J, Kuroda C. Transcatheter chemo-embolization effective for treating hepatocellular carcinoma: a histopathologic study. Cancer. (1984) 54:38792. doi: 10.1002/1097-0142(19840801)54:3<387::AID-CNCR2820540303>3. $0 . \mathrm{CO} ; 2-\mathrm{W}$

14. Takahashi N, Yamada Y, Hoshino K, Kawaida M, Mori T, Abe K, et al. Living donor liver re-transplantation for recurrent hepatoblastoma in the liver graft following complete eradication of peritoneal metastases under indocyanine green fluorescence imaging. Cancers (Basel). (2019) 11:730. doi: 10.3390/cancers11050730

15. Mitani Y, Kubota A, Ueno M, Takifuji K, Watanabe T, Hayami S, et al. Real-time identification of hepatoblastoma using a near infrared imaging with indocyanine green. J Pediat Surg Case Rep. (2014) 2:1803. doi: 10.1016/j.epsc.2014.03.008

16. Yamada Y, Hoshino K, Mori T, Kawaida M, Abe K, Takahashi N, et al. Metastasectomy of hepatoblastoma utilizing a novel overlay fluorescence imaging system. J Laparoendosc Adv Surg Tech A. (2018) 28:11525. doi: 10.1089/lap.2017.0735

17. Souzaki R, Kawakubo N, Matsuura T, Yoshimaru K, Koga Y, Takemoto $\mathrm{J}$, et al. Navigation surgery using indocyanine green fluorescent imaging for hepatoblastoma patients. Pediatr Surg Int. (2019) 35:551-7. doi: 10.1007/s00383-019-04458-5

18. Hunton DB, Bollman JL, Hoffman II HN. Studies of hepatic function with indocyanine green. Gastroenterology. (1960) 39:713-24. doi: 10.1016/S0016-5085(19)35200-X 
19. Speich R, Saesseli B, Hoffmann U, Neftel KA, Reichen J. Anaphylactoid reactions after indocyanine-green administration. Ann Int Medicine. (1988) 109:345-6. doi: 10.7326/0003-4819-109-4-345_2

20. Ishizawa T, Harada N, Muraoka A, Aoki T, Beck Y, Hasegawa K, et al. Scientific basis and clinical application of ICG fluorescence imaging: hepatobiliary cancer. Open Surg Oncol J. (2010) 2:31. doi: 10.2174/1876504101002020031

21. Kudo H, Ishizawa $T$, Tani $K$, Harada N, Ichida A, Shimizu A, et al. Visualization of subcapsular hepatic malignancy by indocyanine-green fluorescence imaging during laparoscopic hepatectomy. Surg Endosc. (2014) 28:2504-8. doi: 10.1007/s00464-014-3468-z

22. Kitai T, Miwa M, Liu H, Beauvoit B, Chance B, Yamaoka Y. Application of near-infrared time-resolved spectroscopy to rat livera preliminary report for surgical application. Phys Med Biol. (1999) 44:2049. doi: 10.1088/0031-9155/44/8/314

23. Kawaguchi Y, Lillemoe HA, Vauthey JN. Dealing with an insufficient future liver remnant: portal vein embolization and two-stage hepatectomy. J Surg Oncol. (2019) 119:594-603. doi: 10.1002/jso.25430
24. Majlesara A, Golriz M, Hafezi M, Saffari A, Stenau E, Maier-Hein L, et al. Indocyanine green fluorescence imaging in hepatobiliary surgery. Photodiagn Photodyn Ther. (2017) 17:208-15. doi: 10.1016/j.pdpdt.2016. 12.005

Conflict of Interest: The authors declare that the research was conducted in the absence of any commercial or financial relationships that could be construed as a potential conflict of interest.

Copyright (c) 2021 Cho, Namgoong, Kwon, Kwon, Kim and Kim. This is an open-access article distributed under the terms of the Creative Commons Attribution License (CC BY). The use, distribution or reproduction in other forums is permitted, provided the original author(s) and the copyright owner(s) are credited and that the original publication in this journal is cited, in accordance with accepted academic practice. No use, distribution or reproduction is permitted which does not comply with these terms. 